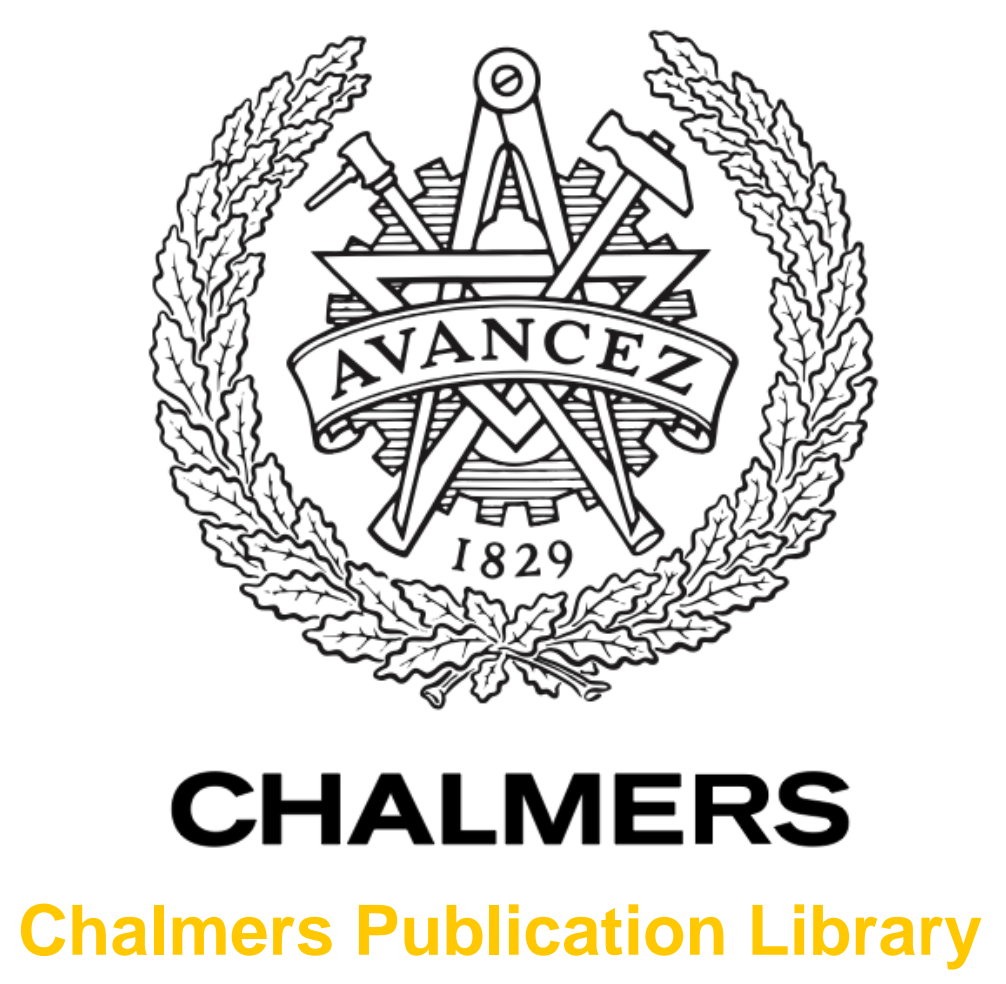

\title{
Microbial risk assessment of drinking water based on hydrodynamic modelling of pathogen concentrations in source water
}

This document has been downloaded from Chalmers Publication Library (CPL). It is the author's version of a work that was accepted for publication in:

Science of the Total Environment (ISSN: 0048-9697)

Citation for the published paper:

Sokolova, E. ; Petterson, S. ; Dienus, O. et al. (2015) "Microbial risk assessment of drinking water based on hydrodynamic modelling of pathogen concentrations in source water".

Science of the Total Environment, vol. 526 pp. 177-186.

http://dx.doi.org/10.1016/j.scitotenv.2015.04.040

Downloaded from: http://publications.lib.chalmers.se/publication/219760

Notice: Changes introduced as a result of publishing processes such as copy-editing and formatting may not be reflected in this document. For a definitive version of this work, please refer to the published source. Please note that access to the published version might require a subscription.

Chalmers Publication Library (CPL) offers the possibility of retrieving research publications produced at Chalmers University of Technology. It covers all types of publications: articles, dissertations, licentiate theses, masters theses, conference papers, reports etc. Since 2006 it is the official tool for Chalmers official publication statistics. To ensure that Chalmers research results are disseminated as widely as possible, an Open Access Policy has been adopted.

The CPL service is administrated and maintained by Chalmers Library. 


\title{
Microbial risk assessment of drinking water based on hydrodynamic modelling of pathogen concentrations in source water
}

Ekaterina Sokolova ${ }^{\mathrm{a}, *}$, Susan Petterson ${ }^{\mathrm{b}, \mathrm{c}}$, Olaf Dienus $^{\mathrm{d}}$, Fredrik Nyström $^{\mathrm{d}, \mathrm{e}}$, Per-Eric Lindgren $^{\mathrm{d}, \mathrm{e}}$ and Thomas J.R. Pettersson ${ }^{\text {a }}$

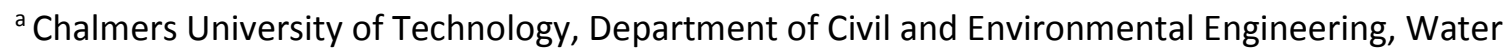
Environment Technology, SE-412 96 Gothenburg, Sweden

*Corresponding author, Tel. +46 31 7721929, e-mail address: ekaterina.sokolova@chalmers.se

${ }^{\mathrm{b}}$ Norwegian University of Life Sciences, Department of Mathematical Sciences and Technology, P.O. Box 5003, NO-1432 Aas, Norway

${ }^{c}$ Water \& Health Pty Ltd, Corlette, NSW 2315, Australia

${ }^{d}$ Ryhov County Hospital, Medical Services, Clinical Microbiology, SE-551 85 Jönköping, Sweden

e Linköping University, Department of Clinical and Experimental Medicine, Medical Microbiology, SE58185 Linköping, Sweden

\begin{abstract}
Norovirus contamination of drinking water sources is an important cause of waterborne disease outbreaks. Knowledge on pathogen concentrations in source water is needed to assess the ability of a drinking water treatment plant (DWTP) to provide safe drinking water. However, pathogen enumeration in source water samples is often not sufficient to describe the source water quality. In this study, the norovirus concentrations were characterised at the contamination source, i.e. in sewage discharges. Then, the transport of norovirus within the water source (the river Göta älv in Sweden) under different loading conditions was simulated using a hydrodynamic model. Based on the estimated concentrations in source water, the required reduction of norovirus at the DWTP was calculated using quantitative microbial risk assessment (QMRA). The required reduction was compared with the estimated treatment performance at the DWTP. The average estimated concentration in source water varied between $4.8 \times 10^{2}$ and $7.5 \times 10^{3}$ genome equivalents $\mathrm{L}^{-1}$; and the average required reduction by treatment was between 7.6 and $8.8 \log _{10}$. The treatment performance at the DWTP was estimated to be adequate to deal with all tested loading conditions, but was heavily dependent on chlorine disinfection, with the risk of poor reduction by conventional treatment and slow sand filtration. To our knowledge, this is the first article to employ discharge-based QMRA, combined with hydrodynamic modelling, in the context of drinking water.
\end{abstract}

Key words: water quality modelling; norovirus; quantitative microbial risk assessment; QMRA; discharge-based QMRA. 


\section{Introduction}

Gastrointestinal diseases related to the contamination of drinking water constitute a major threat to global human health (WHO, 2011). Although this problem is most dominantly present in developing countries, the microbial contamination of drinking water causes outbreaks in developed countries as well (e.g. Braeye et al., 2014; Craun et al., 2010; Larsson et al., 2014; Mac Kenzie et al., 1994). Water is an important transmission route of noroviruses, and human noroviruses are considered a significant cause of waterborne gastroenteritis (Mathijs et al., 2012).

To assess drinking water safety, the World Health Organization recommends a risk-based approach encompassing all steps of the drinking water supply system from the catchment to the consumer (WHO, 2011). In this light, Quantitative Microbial Risk Assessment (QMRA) is widely used to analyse and inform the management of the drinking water supply system (Medema and Smeets, 2009; Smeets et al., 2010). Generic QMRA tools have been developed (Petterson and Stenström, 2007; Schijven et al., 2011) to perform QMRA for specific drinking water treatment plants (DWTPs) with different treatment trains and varying pathogen levels in the source water.

A major limitation of QMRA is constituted by a common lack of proper input data on the pathogen levels in source water. The monitoring of pathogen concentrations in source water is often too infrequent. However, pathogen concentrations in water sources are driven by upstream loading events and are highly variable, with peaks that can occur suddenly and may disappear within only a few hours (Åström et al., 2007; Westrell et al., 2006b). Thus, monitoring processes often fail to detect potentially hazardous peaks in pathogen concentrations. In addition, detection limits of analytical methods can be higher than pathogen concentrations relevant to public health. Therefore, monitoring data could provide misleading input for QMRA. This could negatively impact the safety of the produced drinking water and the health of consumers.

In order to address the limitation regarding the lack of source water quality data, the monitoring data can be supplemented by the results of hydrodynamic modelling (McBride et al., 2012). Hydrodynamic modelling has proven to be useful in order to describe the microbial water quality in water sources and to assess the influence of different conditions and events (e.g. Liu et al., 2006; Sokolova et al., 2013). Thus, a hydrodynamic model can be used to simulate the influence of upstream loading events on the source water quality at the intake of a DWTP.

The aim of this article was to quantify the impact of upstream loading events on the health risks for drinking water consumers. For this purpose, hydrodynamic modelling and QMRA approaches were combined. The norovirus concentrations in the source water during various upstream loading conditions were quantified using hydrodynamic modelling. Based on the modelling results, the required reduction of norovirus concentrations at the DWTP was calculated and compared with the estimated performance of the DWTP. To our knowledge, this article is the first to employ dischargebased QMRA, combined with hydrodynamic modelling, in the context of drinking water management. 


\section{Methods}

\subsection{Study area}

The Överby DWTP produces drinking water for approximately 49000 consumers in the municipality of Trollhättan in Sweden. The Överby DWTP draws water from the river Göta älv and employs the following treatment steps: coagulation/flocculation, rapid sand filtration, slow sand filtration and free chlorine disinfection.

Göta älv is a river that drains Lake Vänern into the strait Kattegat. The length of the river between the outflow from Lake Vänern and the mouth of the river is $93 \mathrm{~km}$. The water flow in the river Göta älv is regulated by several hydropower stations. In this study we focus on the $11 \mathrm{~km}$ stretch of the river between the Vargön and Trollhättan hydropower stations. In 2011, the water flow in the studied part of the river varied between 138 and $898 \mathrm{~m}^{3} / \mathrm{s}$, with an average of $575 \mathrm{~m}^{3} / \mathrm{s}$.

The virus contamination at the intake can be caused by sewage discharges into the river from faecal sources located upstream the Överby DWTP: the Holmängen wastewater treatment plant (WWTP) and the sewage pumping stations. The Holmängen WWTP treats sewage from approximately 27000 persons. The treatment at the Holmängen WWTP consists of the following treatment steps: rotating screens, aerated grit chambers, aeration tank, primary sedimentation tank, trickling filter, denitrification, flocculation tanks and sedimentation tanks. By-passes of untreated sewage are possible, but occur relatively seldom - approximately once a year. Untreated sewage often enters the river during the periods of heavy rain through emergency discharges from the pumping stations.

\subsection{Quantification of norovirus concentrations in sewage}

A norovirus monitoring campaign was undertaken as a part of the European Union project VISK (visk.nu). During the monitoring campaign, the sewage from the inflow and outflow of the Holmängen WWTP was sampled daily from 15 to 29 February $2012(n=15)$. Each of these days, the sewage was collected over 24 hours using an automated sampler, which was flow rate driven. The sewage volume used for analysis was $50 \mathrm{~mL}$. The sewage was analysed for norovirus genogroups I and II (GGI and GGII) using quantitative real-time PCR (qPCR) based on reported methods (Dienus et al., 2015; Kageyama et al., 2003; Nordgren et al., 2009; Shieh et al., 1995) as described in Appendix A. The GGI and GGII were chosen, since they constitute the most important norovirus genogroups in terms of human infection (Matthews et al., 2012). The qPCR analysis determined the concentration of norovirus genome equivalents.

The obtained qPCR data (Table 1) (Dienus et al., 2015) were used to characterise the probability density functions for norovirus GGI and GGII in raw and treated sewage from the Holmängen WWTP. The virus concentrations were assumed to follow a gamma distribution with parameters $\rho$ (shape) and $\lambda$ (scale):

Equation 1

$$
f(c \mid \lambda, \rho)=\frac{e^{-\frac{c}{\lambda}} \lambda^{-\rho} c^{-1+\rho}}{\Gamma[\rho]}
$$


The gamma distribution was then used to calculate the likelihood function for each dataset of reported concentrations $\left(c_{1}, c_{2} \ldots . c_{15}\right)$ :

Equation 2

$$
L\left(\lambda, \rho \mid c_{i}\right)=\prod_{i=1}^{15} f\left(\lambda, \rho \mid c_{i}\right)
$$

The likelihood functions were optimised (in Mathematica 8.0) to obtain maximum likelihood estimators of $\rho$ and $\lambda$ for each of the four datasets.

Table 1 Summary of reported norovirus GGI and GGII concentrations (genome equivalents $\mathrm{L}^{-1}$ ) in raw and treated sewage from the Holmängen WWTP during daily sampling in February 2012

\begin{tabular}{llllll}
\hline & Sewage & $\mathrm{n}$ (detects) & Min & Max & Mean \\
\hline GGI & Raw & $15(15)$ & $8.0 \times 10^{4}$ & $1.7 \times 10^{6}$ & $6.9 \times 10^{5}$ \\
& Treated & $15(15)$ & $1.2 \times 10^{5}$ & $4.5 \times 10^{5}$ & $2.8 \times 10^{5}$ \\
\hline GGII & Raw & $15(15)$ & $4.2 \times 10^{5}$ & $4.8 \times 10^{6}$ & $2.7 \times 10^{6}$ \\
& Treated & $15(15)$ & $8.9 \times 10^{4}$ & $1.7 \times 10^{6}$ & $1.0 \times 10^{6}$ \\
\hline
\end{tabular}

\subsection{Hydrodynamic modelling}

To simulate the transport of norovirus within the river Göta älv, a hydrodynamic model was set up. A three-dimensional time-dependent hydrodynamic model was used - MIKE 3 FM (MIKE Powered by DHI software package). This hydrodynamic model is based on the numerical solution of threedimensional incompressible Reynolds averaged Navier-Stokes equations invoking the assumptions of Boussinesq and of hydrostatic pressure (DHI, 2011). The model consists of continuity and momentum equations and is closed by a turbulent closure scheme (DHI, 2011). The water density was assumed to be homogenous (barotropic formulation).

The modelling domain was approximated with prisms (triangles in horizontal plane) using a flexible mesh approach. The length of the triangles' sides varied from approximately 40 to $90 \mathrm{~m}$. In vertical direction, the river was divided into 10 layers with a thickness that could vary depending on the depth and water surface elevation in the river (sigma-layers).

The initial conditions in the river were defined by the water surface elevation. The upstream and downstream boundary conditions were defined by the water flow through the Vargön hydropower station and the water surface elevation at the Trollhättan hydropower station (data provided by the hydropower company Vattenfall), respectively. On the land boundary, the normal component of velocity was set to zero. The horizontal and vertical eddy viscosities were simulated using Smagorinsky and Log law formulations, respectively (DHI, 2011). The bed resistance was described by a constant roughness height of $0.05 \mathrm{~m}$. The model was run using default parameterisation (DHI, 2011).

The hydrodynamic model was applied to simulate the impact of sewage discharges on the norovirus GGI and GGII concentration at the water intake. Variability exists in both sewage discharges and river flow conditions. To represent the overall range of variability, the selected scenarios regarding sewage 
discharges were simulated for conditions of low $\left(138 \mathrm{~m}^{3} / \mathrm{s}\right)$, average $\left(575 \mathrm{~m}^{3} / \mathrm{s}\right)$ and high $\left(898 \mathrm{~m}^{3} / \mathrm{s}\right)$ water flow in the river. The following scenarios were selected:

- Baseline conditions

o Regular discharge from the Holmängen WWTP - discharge of treated sewage

- Continuous discharge of average magnitude $\left(0.2 \mathrm{~m}^{3} / \mathrm{s}\right)$

- Continuous discharge of peak magnitude $\left(0.67 \mathrm{~m}^{3} / \mathrm{s}\right)$

- Loading events

0 By-pass at the Holmängen WWTP - discharge of raw sewage

- 1 day pulse discharge of average magnitude $\left(0.2 \mathrm{~m}^{3} / \mathrm{s}\right)$

- 1 day pulse discharge of peak magnitude $\left(0.67 \mathrm{~m}^{3} / \mathrm{s}\right)$

- 1 hour pulse discharge of average magnitude $\left(0.2 \mathrm{~m}^{3} / \mathrm{s}\right)$

- 1 hour pulse discharge of peak magnitude $\left(0.67 \mathrm{~m}^{3} / \mathrm{s}\right)$

o Pumping station overflow - discharge of raw sewage

- 3 hour pulse discharge of $550 \mathrm{~m}^{3}$

- 1 hour pulse discharge of $550 \mathrm{~m}^{3}$

Norovirus contamination was simulated as a passive substance, i.e. the decay and settling of norovirus in the water source were not taken into account.

The Holmängen WWTP is located approximately $9.5 \mathrm{~km}$ upstream the Överby DWTP. Since the model only covers the part of the river between the hydropower stations, discharges from the Holmängen WWTP were assumed to enter the river on the upper boundary of the model (the Vargön hydropower station), i.e. approximately $6 \mathrm{~km}$ upstream the Överby DWTP and approximately $3.5 \mathrm{~km}$ closer to the Överby DWTP than in reality.

In the municipality of Vänersborg there is a number of pumping stations from which overflows may occur. Based on the proximity of these pumping stations to the river Göta älv and the data on the total volumes of overflows from each pumping station during year 2011, several pumping stations could be potentially relevant for the water quality in the river Göta älv. For the purpose of this study, one pumping station, located approximately $3 \mathrm{~km}$ upstream the Överby DWTP was selected.

Using the modelling results and the quantified concentrations in the sewage, the peak norovirus concentrations in the source water at the intake were calculated for each loading event.

\subsection{Quantitative microbial risk assessment}

The hydrodynamic model provided a time series of concentration at the water intake in response to each simulated contamination condition. For each peak contamination level, Equation 3 was used to find the required $\log _{10}$ reduction to achieve the health target. The health target suggested by the World Health Organization for drinking water was used: $1 \times 10^{-6}$ DALY (disability adjusted life years) per person per annum (WHO, 2011), which can be translated to $2.74 \times 10^{-9}$ DALY per person per day. By complying with the daily target, an even stricter requirement than the annual target is fulfilled. Equation 3

$$
\text { Health target }=D A L Y \times\left(1-e^{\left(-r \times C \times V \times 10^{-L R}\right)}\right)
$$

where: 
- DALY is the DALY weight per infection $\left(7.16 \times 10^{-4}\right)$ calculated using data on the population structure of Sweden in 2010 and data on age dependency of health outcomes, duration and severity factors for viral infections (reanalysis of data given by Kemmeren et al. (2006)).

- $r$ is the coefficient of the exponential dose-response function. The infectivity of norovirus was described by the exact beta-Poisson model $(\alpha=0.04, \beta=0.055$; infectivity parameter values fitted to combined dataset, dose in genome equivalents $L^{-1}$ ) (Teunis et al., 2008). The exact beta-Poisson model can be simplified to the exponential model at low doses with $r=\alpha /(\alpha+\beta)=0.42$ (i.e. the expected value of the beta distribution).

- $C$ is the estimated norovirus concentration (GGI+GGII) in source water (genome equivalents $\mathrm{L}^{-}$ $\left.{ }^{1}\right)$. It is known from previous studies that only a small fraction of virus particles is infectious (Hewitt et al., 2011). On the other hand, the virus enrichment process and extraction of viral RNA followed by cDNA synthesis result in detection of only a small fraction of virus particles. To avoid underestimation of the health risks, in this study it was thus assumed that all virus particles detected by qPCR were infectious.

- $\quad V$ is the exposure volume (L). The mean of the volume of unheated water consumed in Sweden as described by a Log-Normal distribution ( $\mu=-0.299, \square=0.57$ ) (Westrell et al., 2006a) was 0.74 L.

- $L R$ is the treatment performance of the DWTP ( $\log _{10}$ reduction).

\subsection{Evaluation of the drinking water treatment plant performance}

The Överby DWTP consists of three process barriers: (i) coagulation/flocculation, sedimentation and rapid sand filtration (together referred to as conventional treatment), (ii) slow sand filtration and (iii) free chlorine disinfection. The performance of the Överby DWTP was evaluated based on routine monitoring data and reported values in the literature.

As part of the routine monitoring program undertaken at the Överby DWTP (Table 2), samples were collected and analysed for E. coli in source water (weekly samples between 29 September 2008-2 October 2012; $n=212$ ), after rapid sand filtration and after slow sand filtration (monthly samples each from 1 December 2008 - 4 September $2012(n=44))$. Results were reported in colony forming units (CFU) per $100 \mathrm{~mL}$ and included left (<) (all datasets) and right (>) (source water only) censored outcomes.

The removal of $E$. coli across rapid sand filtration and slow sand filtration was quantified by constructing a statistical model appropriate for describing microbial counts following the approach presented by Teunis et al. (1999) and modified for the left and right censoring of the current dataset (see also Appendix B). Variable and constant fraction removal models were compared to obtain the best estimate of the $\log _{10}$ reduction by filter line for each barrier.

The reduction of norovirus by free chlorine disinfection was estimated based on the mean Ct values for the disinfection contact chamber at the Överby DWTP and literature data on the sensitivity of norovirus surrogates to free chlorine disinfection. 
Table 2 Summary of reported historical E. coli data from the Överby DWTP monitoring program

\begin{tabular}{|c|c|c|c|c|}
\hline & \multicolumn{4}{|c|}{ Summary of reported E. coli data } \\
\hline \multicolumn{5}{|c|}{ Source water (29 September $2008-2$ October 2012) } \\
\hline Detects (total $n=212$ ) & \multicolumn{4}{|c|}{175} \\
\hline $\begin{array}{l}\text { Right censored (> variable limit, } \\
\text { maximum } 100 \mathrm{CFU} 100 \mathrm{~mL}^{-1} \text { ) }\end{array}$ & \multicolumn{4}{|l|}{39} \\
\hline Mean ${ }^{\mathrm{a}}\left(\mathrm{CFU} 100 \mathrm{~mL}^{-1}\right)$ & \multicolumn{4}{|l|}{21} \\
\hline \multicolumn{5}{|c|}{ Post rapid sand filtration (1 December 2008 - 4 September 2012) } \\
\hline & Filter 1 & Filter 2 & Filter 3 & Filter 4 \\
\hline Detects (total $n=44$ ) & 6 & 7 & 8 & 1 \\
\hline $\operatorname{Max}\left(\right.$ CFU $\left.100 \mathrm{~mL}^{-1}\right)$ & 3 & 12 & 5 & 1 \\
\hline \multicolumn{5}{|c|}{ Post slow sand filtration (1 December 2008 - 4 September 2012) } \\
\hline & Filter 1 & Filter 2 & Filter 3 & Filter 4 \\
\hline Detects (total $n=44$ ) & 1 & 1 & 1 & 1 \\
\hline $\operatorname{Max}\left(C F U 100 \mathrm{~mL}^{-1}\right)$ & 1 & 3 & 1 & 2 \\
\hline
\end{tabular}

${ }^{a}$ Arithmetic mean with left censored data equal to the detection limit and right censored data equal to the maximum detection.

\section{Results and Discussion}

In this study, the pathogen concentrations at the water intake were estimated using the pathogen concentrations characterised at the contamination source and hydrodynamic modelling. Based on the estimated concentrations in source water and the health target, the required levels of water treatment at the DWTP were calculated using QMRA. In this way, we implement discharge-based QMRA, as suggested by McBride et al. (2013), and integrate it with hydrodynamic modelling, as recommended by McBride et al. (2012). The novelty of this work lies in the combination of these two approaches in the context of drinking water management.

\subsection{Norovirus concentrations in sewage}

The norovirus GGI and GGIl concentrations in raw and treated sewage were described by gamma distributions (Figure 1). The expected values of norovirus concentration in raw and treated sewage, and the parameters of the gamma distributions are summarised in Table 3. The mean norovirus reduction at the Holmängen WWTP was $0.39 \log _{10}$ for GGI and $0.41 \log _{10}$ for GGII.

Thus, despite the treatment train at the Holmängen WWTP, norovirus reduction was poor, and the norovirus concentration in treated sewage was approximately $10^{5}-10^{6}$ genome equivalents $\mathrm{L}^{-1}$ (Table 3). Moreover, since the sewage at the Holmängen WWTP is not disinfected, the viruses discharged into the river with treated sewage are likely to be as infectious as in raw sewage.

Quantitative predictions of infectious norovirus particles using qPCR analysis are subjected to a number of uncertainties (Hewitt et al., 2011; Rutjes et al., 2009; Thebault et al., 2013). First of all, only a small fraction of the virus particles is infectious (Hewitt et al., 2011). Furthermore, uncertainties are associated with the efficiency of virus enrichment procedure, the RNA extraction, CDNA synthesis and the qPCR. These uncertainties are outside of the scope of this article and are discussed elsewhere (Dienus et al., 2015). 
Since the norovirus concentrations in sewage were quantified using samples collected in February, these concentrations represent a specific period rather than a full year. The incidence of norovirus gastroenteritis in the population is generally the highest during wintertime (Pérez-Sautu et al., 2012; Rohayem, 2009; Verhoef et al., 2008). Consequently, the selected period is associated with high virus loading and represents the time of the highest risks for drinking water consumers. Therefore, looking only at this period may result in overestimation of the annual risk.

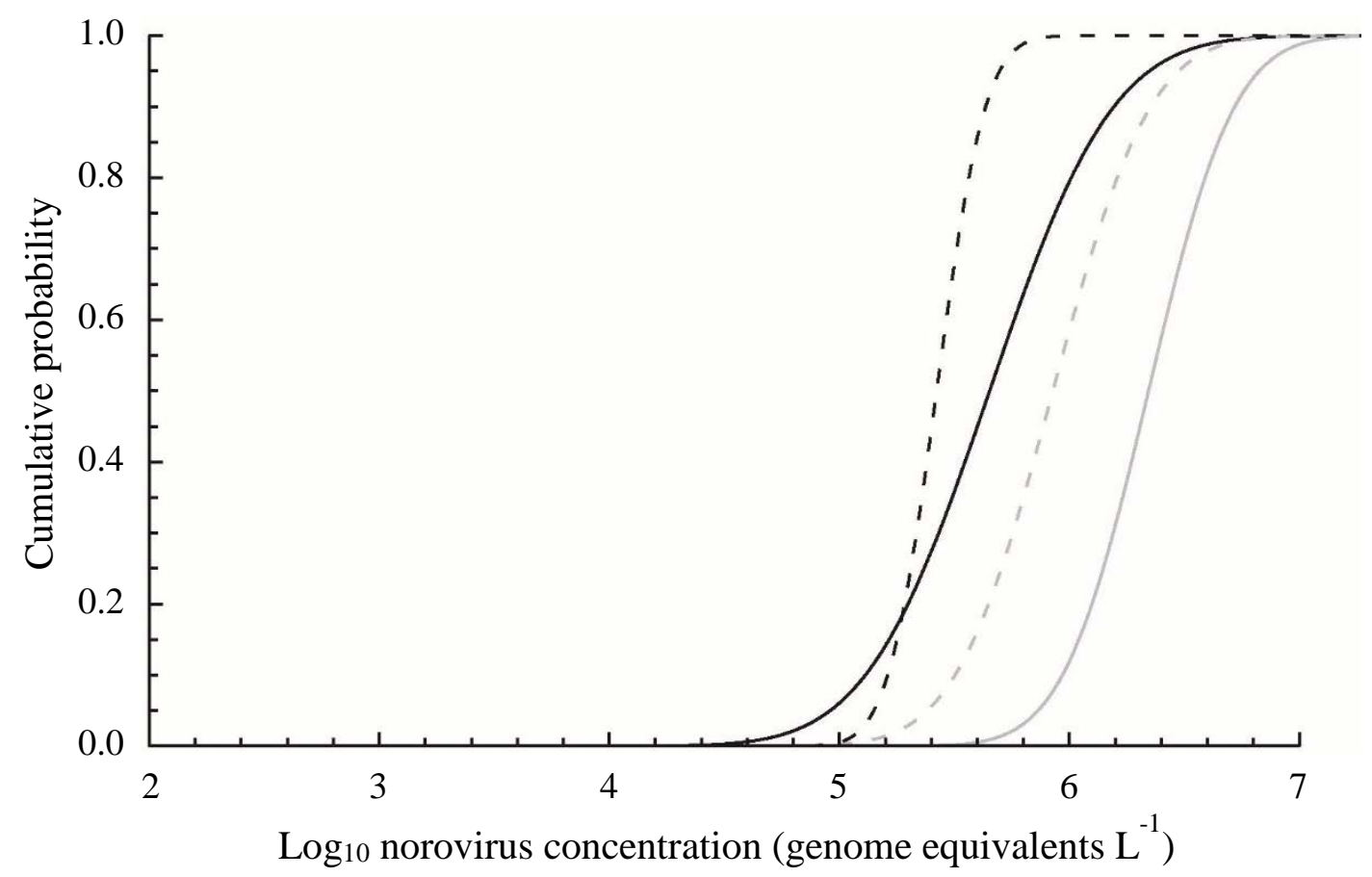

Figure 1 Concentration of norovirus GGI (black colour) and GGII (grey colour) in raw (continuous line) and treated (dotted line) sewage at the Holmängen WWTP. The cumulative density function shows the variability in the sewage concentration.

Table 3 Maximum likelihood gamma distribution parameters fitted to reported norovirus GGI and GGII concentrations (genome equivalents $\mathrm{L}^{-1}$ ) in raw and treated sewage from the Holmängen WWTP during February 2012

\begin{tabular}{lllllll}
\hline \multicolumn{3}{c}{ GGI } & \multicolumn{5}{l}{ GGII } \\
\hline Sewage & $\rho$ & $\lambda$ & $\mathrm{E}(\mathrm{c})^{\mathrm{a}}$ & $\rho$ & $\lambda$ & $\mathrm{E}(\mathrm{c})^{\mathrm{a}}$ \\
\hline Raw & 1.3 & $5.2 \times 10^{5}$ & $6.8 \times 10^{5}$ & 2.9 & $9.3 \times 10^{5}$ & $2.7 \times 10^{6}$ \\
Treated & 7.7 & $3.7 \times 10^{4}$ & $2.8 \times 10^{5}$ & 2.7 & $3.8 \times 10^{5}$ & $1.0 \times 10^{6}$ \\
\hline
\end{tabular}

${ }^{a}$ Expected value of concentration $(\lambda \rho)$

\subsection{Estimated norovirus concentrations in source water and required norovirus reduction by treatment}

The estimated peak norovirus concentrations at the water intake under baseline conditions (regular discharge of treated sewage) are illustrated in Figure 2. According to the modelling results, the regular discharge from the Holmängen WWTP is an important source of viruses in the source water (Figure 2, Table 4). 
The results for the loading events are summarised in Table 4 . The loading events, when the pumping station overflows and by-passes at the WWTP are triggered by rainfall and surface runoff, lead to increased virus concentrations in the source water. Interestingly, the estimated concentrations at the water intake under baseline conditions were similar to the concentrations caused by loading events (Table 4). Of these events, the one-day-long overflow of untreated sewage resulted in the highest concentration at the water intake (Table 4). The transport time in the river for this study area was short. After the occurrence of an event, it took between 2 and 40 hours before the peak concentration arrived at the water intake (Table 4), depending on the type of event and the river flow conditions. It may be possible to avoid drawing water from the river during such events, if these events would be registered in time.

In this study, the hydrodynamic model provided a conservative estimation of the virus concentrations at the water intake, since the decay and settling of viruses in the water source were not taken into account. Norovirus is highly resistant to environmental degradation in water (Bae and Schwab, 2008; Ngazoa et al., 2008; Seitz et al., 2011). For example, Bae and Schwab (2008) reported the nucleic acid decay of the prototype human norovirus to be $0.08 \pm 0.02 \log _{10}$ per day in surface water at $25^{\circ} \mathrm{C}$. Therefore, given that (i) the water temperature in the river Göta älv is on average $8{ }^{\circ} \mathrm{C}$ and does not exceed $23^{\circ} \mathrm{C}$, and that (ii) in our study, the transport times in the river are on a scale of hours rather than days (Table 4), the overestimation of the norovirus concentrations at the water intake, due to the assumption of no decay, can be neglected. Viruses can adsorb on the surface of particles (Bellou et al., 2015; Wong et al., 2012) that can settle or resuspend (Xagoraraki et al., 2014). The settling of viruses was not accounted for due to (i) the complexity of this process and the involved uncertainty summarised by Hipsey et al. (2008), and, (ii) similarly to decay, the fact that settling is likely to have a minor influence on the results of this study, due to the short transport times in the water source (Table 4).

The level of water treatment required to cope with the negative effects of the tested scenarios on the source water quality (Table 4 ) was calculated using QMRA. The average required reduction of norovirus at the Överby DWTP varied for different scenarios between 7.6 and $8.8 \log _{10}$ (Table 4).

The results of the hydrodynamic modelling provided information regarding the relative magnitude and, thus, the importance of upstream loading events, as well as information on the time between the occurrence of an event and the arrival of the peak concentration at the water intake. In this way, the modelling results provided information for managing the operation of the Överby DWTP in terms of the required level of treatment and the response time to upstream incidents. The modelling results provided information about the impact of different contamination sources. This information can be used to apply mitigation measures at the contamination source (in the catchment) to protect the water quality in the drinking water source. 


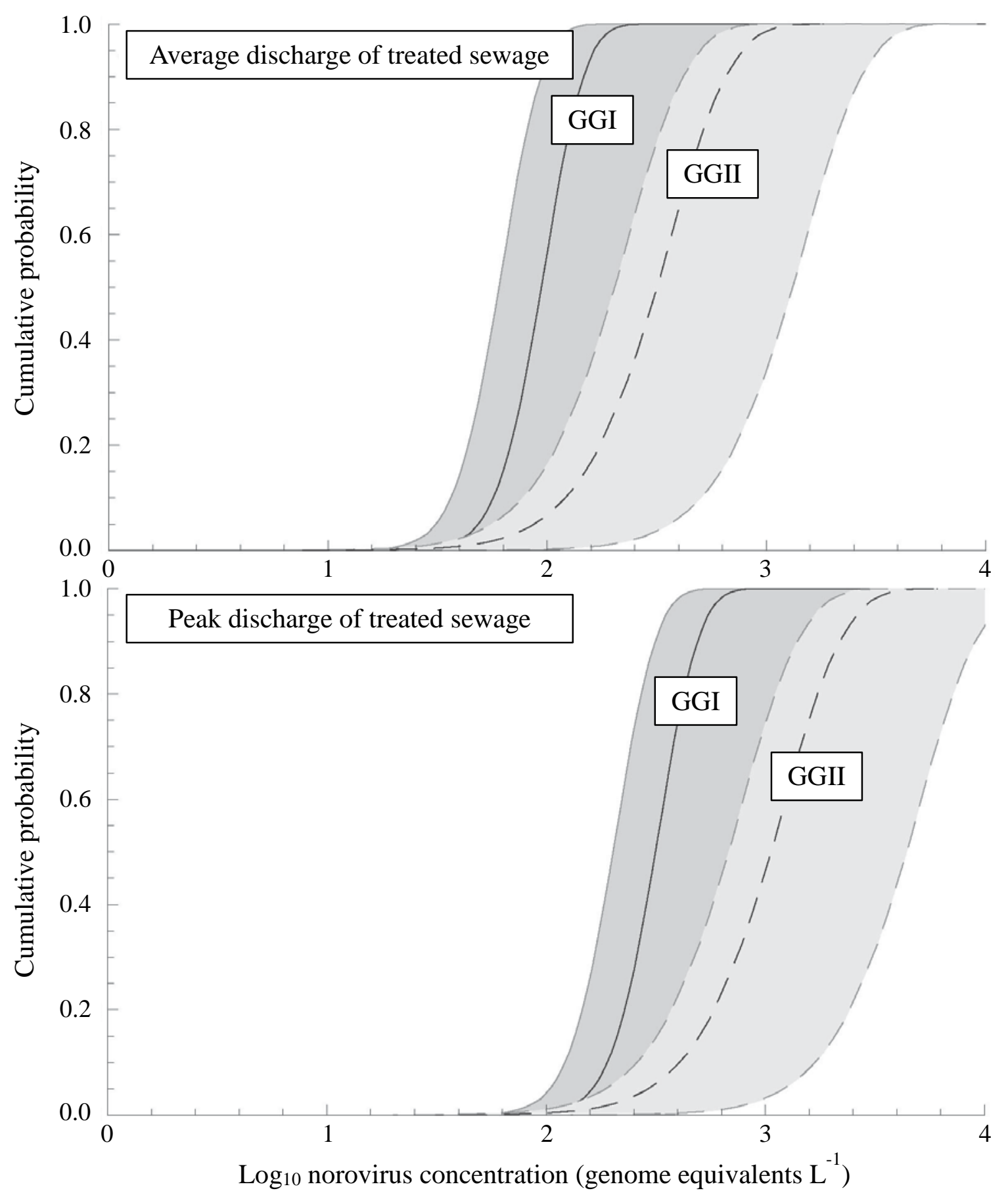

Figure 2 Modelling results: concentration of norovirus GGI and GGII at the intake of the Överby DWTP due to regular discharge (baseline conditions) from the Holmängen WWTP. The cumulative density function shows the variability in the sewage concentration, the shaded range indicates the variability due to the river flow conditions. The left hand boundary is for high flow conditions; the right hand boundary is for low flow conditions. 
Table 4 Estimated influence of upstream discharges on the total norovirus (GGI and GGII) concentration at the intake of the Överby DWTP and the required norovirus reduction by treatment

\begin{tabular}{|c|c|c|c|c|c|}
\hline & & $\begin{array}{l}\text { Discharge } \\
\text { magnitude }\end{array}$ & $\begin{array}{l}\text { Peak concentration } \\
\text { at intake }{ }^{\text {a }} \\
\text { [genome equivalents } \cdot \mathrm{L}^{-1} \text { ] }\end{array}$ & $\begin{array}{l}\text { Required } \\
\text { reduction a } \\
{\left[\log _{10}\right]}\end{array}$ & $\begin{array}{l}\text { Time to } \\
\text { arrival at intake }{ }^{b} \\
\text { [days, hours, min] }\end{array}$ \\
\hline \multirow{2}{*}{ Baseline } & $\begin{array}{l}\text { Discharge WWTP } \\
\text { treated sewage }\end{array}$ & Mean & $8.7 \times 10^{2}\left(3.3 \times 10^{3}\right)$ & $7.9(8.4)$ & \\
\hline & continuous & Peak & $2.9 \times 10^{3}\left(1.1 \times 10^{4}\right)$ & $8.4(9.0)$ & \\
\hline \multirow{6}{*}{ Events } & $\begin{array}{l}\text { By-pass WWTP } \\
\text { raw sewage }\end{array}$ & Mean & $2.2 \times 10^{3}\left(2.9 \times 10^{4}\right)$ & $8.3(9.4)$ & $(0,13,0)$ \\
\hline & 1 day pulse & Peak & $7.5 \times 10^{3}\left(8.6 \times 10^{4}\right)$ & $8.8(9.8)$ & $(1,16,10)$ \\
\hline & $\begin{array}{l}\text { By-pass WWTP } \\
\text { raw sewage }\end{array}$ & Mean & $7.0 \times 10^{2}\left(1.6 \times 10^{3}\right)$ & $7.8(8.1)$ & $(0,4,20)$ \\
\hline & 1 hour pulse & Peak & $2.4 \times 10^{3}\left(5.4 \times 10^{3}\right)$ & $8.3(8.6)$ & $(0,23,20)$ \\
\hline & \multirow{2}{*}{$\begin{array}{l}\text { Pumping station } \\
\text { overflow } \\
\text { raw sewage }\end{array}$} & $\begin{array}{l}3 \text { hour } \\
550 \mathrm{~m}^{3}\end{array}$ & $4.8 \times 10^{2}\left(1.7 \times 10^{3}\right)$ & $7.6(8.1)$ & $(0,3,10),(0,11,50)$ \\
\hline & & $\begin{array}{l}1 \text { hour } \\
550 \mathrm{~m}^{3}\end{array}$ & $8.3 \times 10^{2}\left(2.1 \times 10^{3}\right)$ & $7.8(8.2)$ & $(0,2,20),(0,10,45)$ \\
\hline
\end{tabular}

${ }^{a}$ Mean (Upper $95^{\text {th }}$ percentile). The variability is due to the variability in the sewage concentration, in flow conditions in the river and due to underlying assumptions for QMRA.

${ }^{b}$ Time from the event to arrival of the peak concentration at the intake. Range indicates the minimum and maximum travel times under different river flow conditions.

\subsection{Expected norovirus reduction at the drinking water treatment plant}

\subsubsection{Conventional treatment}

For conventional treatment with rapid sand filtration, the estimated reduction of $E$. coli varied between filtration lines from 1.8 to $3.2 \log _{10}$ (Table 5 , Appendix B). When data for all filtration lines were combined, the overall reduction across the conventional barrier was best fit by the model allowing for (beta distributed) variability in removal. The expected value of the beta distribution was $2.0 \log _{10}$ reduction. Hijnen and Medema (2010) reviewed six studies regarding the reduction of bacteria by full-scale conventional treatment processes. The average reported reduction varied between studies from 1.3 to 3.4, with a mean elimination capacity (MEC - weighted average defined within the review giving consideration to quality and representativity of the data) of $2.1 \log _{10}$. This variability in reported values from the literature is of a similar range to the variability observed between treatment lines at the Överby DWTP. There is no reported correlation between E. coli and virus reduction across conventional treatment. However, the comparison with published studies may provide a reference point for how well the Överby DWTP is performing in comparison to other DWTPs. 
In the absence of information on virus reduction for the Överby DWTP, and given the consistency between E. coli reduction at the Överby DWTP and the literature data on bacteria reduction, the reported range of virus reduction from the literature was considered applicable for the Överby DWTP. Hijnen and Medema (2010) reviewed seven studies concerning virus reduction across conventional treatment. The authors reported that the reduction of virus was on average $1 \log _{10}$ higher than of bacteria and varied from 1.2 to $5.3 \log _{10}$ with a MEC of 3.0.Thus, norovirus reduction at the Överby DWTP was assumed to be on average $3.0 \log _{10}$ and vary between 1.2 and $5.3 \log _{10}$.

Table 5 Estimated $\log _{10}$ reduction of $E$. coli by filtration line and for combined effluent for rapid sand filtration and slow sand filtration treatment barriers at the Överby DWTP

\begin{tabular}{|c|c|c|c|c|c|}
\hline \multirow[t]{2}{*}{ Rapid sand filtration } & \multicolumn{4}{|c|}{ Filtration line } & \multirow[t]{2}{*}{ Combined effluent $^{a}$} \\
\hline & 1 & 2 & 3 & 4 & \\
\hline $\log _{10}$ reduction & 2.2 & 1.8 & 1.9 & 3.2 & 2.0 \\
\hline \multirow[t]{2}{*}{ Slow sand filtration } & \multicolumn{4}{|c|}{ Filtration line } & Combined effluent \\
\hline & 1 & 2 & 3 & 4 & \\
\hline $\log _{10}$ reduction & 1.1 & 0.6 & 1.1 & 0.8 & 0.9 \\
\hline
\end{tabular}

a Expected value of the beta distribution $\left(-\log _{10}\left(\frac{\alpha}{\alpha+\beta}\right)\right)$ describing variable reduction efficacy (see Appendix B)

\subsubsection{Slow sand filtration}

For slow sand filtration, the reduction of $E$. coli varied between filtration lines from 0.6 to $1.1 \log _{10}$ (Table 5, Appendix B). The ability to demonstrate the reduction was limited by a low number of detects before slow sand filtration, and hence only a low reduction could be observed.

Hijnen and Medema (2010) reviewed nine studies related to the reduction of viruses by slow sand filtration, but only one study was conducted at full scale, and reported rates were low and variable (0.6 - 4.0 $\log _{10}$ with MEC=2.2). Another study analysed data from full scale seeding experiments using MS2 bacteriophages, and reported that median $\log _{10}$ reduction varied between experiments from 0.5 to 3.8 (Teunis et al., 2009).

In the absence of information on virus reduction by the slow sand filters at the Överby DWTP, the reported range from the literature (Hijnen and Medema, 2010) was considered applicable to describe norovirus reduction at the Överby DWTP. Thus, norovirus reduction at the Överby DWTP was assumed to be on average $2.2 \log _{10}$ and vary between 0.6 and $4.0 \log _{10}$.

\subsubsection{Free chlorine disinfection}

The chlorine disinfection contact chamber at the Överby DWTP has a mean hydraulic residence time of 86.4 minutes. The average of daily free chlorine measurements $(n=386)$ within the chamber was $0.1 \mathrm{mg} \mathrm{L}^{-1}$. The mean $\mathrm{Ct}$ across the contact chamber is therefore on average $8.64 \mathrm{mg} \mathrm{L}^{-1} \mathrm{~min}^{-1}$. Since it is so far not possible to cultivate human norovirus under laboratory conditions, surrogates, such as feline calicivirus and murine norovirus, have to be used (Bae and Schwab, 2008). Studies investigating the sensitivity of norovirus surrogates to free chlorine disinfection have reported that a $\mathrm{Ct}$ of 0.32 and $0.31 \mathrm{mg} \mathrm{L}^{-1} \mathrm{~min}^{-1}$ was sufficient for $4 \log _{10}$ inactivation of feline calicivirus (Thurston-Enriquez et al., 2003) and murine norovirus (Cromeans et al., 2010; Kahler et al., 2010; Lim et al., 2010), 
respectively. Assuming linear inactivation, this susceptibility would imply a very low probability of norovirus survival across the contactor at the Överby DWTP.

However, short circuiting of the contactor can lead to small portions of flow receiving very low dosage of chlorine, which may translate to thousands of litres of water with low virus inactivation distributed to the consumers. Therefore, achieving high reduction and safety for the consumers via the chlorine disinfection step is dependent upon good hydraulic behaviour of the contactor (Petterson and Stenström, 2015).

\subsubsection{Overall norovirus reduction}

The estimated overall mean reduction implies that the Överby DWTP complies with the target of $10^{-6}$ DALY per person per annum under all modelled loading conditions. However, variability in treatment performance is a critical factor to be considered. The overall reduction is heavily dependent upon effective chlorine disinfection, with the potential for very poor reduction by conventional treatment and slow sand filtration. Were this poor reduction by conventional treatment and/or slow sand filtration to coincide with shielding and possible short circuiting of the disinfection contactor, the treatment performance would be considerably reduced. Moreover, the treatment processes are interdependent, i.e. poor coagulation is likely to cause filter breakthrough and decreased reduction by chlorination. Understanding more of site-specific treatment performance, dependent on such factors as e.g. temperature, schmutzdecke age, sand grain size, characteristics of the disinfection contactor, would be beneficial. The estimation of the performance of different treatment barriers indicated which improvements within the DWTP can be made.

\section{Conclusions}

The outcomes of this study have important implications for understanding and managing the norovirus risks associated with the Överby DWTP:

- The regular discharge of treated sewage from the Holmängen WWTP is an important source of norovirus loading at the water intake. Measures to reduce the norovirus concentration in the treated sewage could provide an effective reduction in norovirus loading to the river under baseline conditions.

- The hydrodynamic modelling results provided information regarding the reaction time available between an upstream event and the norovirus load reaching the water intake. Notification strategies between the WWTP and the DWTP would allow for (i) selective abstraction to avoid the most contaminated source water, and/or (ii) proactive monitoring of coagulant dosage to ensure an optimal plant operation.

- Given what is known about norovirus loading in the river Göta älv and the expected performance of the treatment, the Överby DWTP is able to provide sufficient removal of viruses to meet the target of $10^{-6}$ DALY per person per annum.

- Meeting safe drinking water targets at the Överby DWTP is strongly dependent upon effective free chlorine disinfection. Limited information was available regarding the hydraulic behaviour of the disinfection contactor. Hence, the hydraulic behaviour of the contactor needs to be characterised to ensure a suitable minimum residence time. 
It can be concluded that hydrodynamic models of water sources combined with QMRA provide valuable decision support for risk management, because they can be used:

- to simulate the effects of short term events that may be important for driving downstream risks, but cannot be captured by monitoring water quality at the water intake;

- to provide information on the relative importance of different sources and loading events for surface waters that are influenced by several upstream sources.

\section{Acknowledgements}

This research was funded by the Graduate School on Environment and Health (Forskarskolan Miljö och Hälsa) financed by the Chalmers University of Technology, the University of Gothenburg and Region Västra Götaland, Sweden; the European Union project VISK (Interreg IV A program); the Swedish Water and Wastewater Association (Svenskt Vatten). The authors are also grateful to: Trollhättan Energi and the municipality of Vänersborg for providing data for this research and valuable discussions; DHI for providing the license for the MIKE Powered by DHI software and modelling support.

\section{Appendix A: Methodology for norovirus analysis}

The description of the methodology for norovirus (NoV) analysis in sewage is based on Dienus et al. (2015).

\section{Enrichment from sewage}

Sewage samples were processed the same day as they were sampled. $50 \mathrm{~mL}$ of each sample was spiked with $5 \mu \mathrm{L}$ murine norovirus 1 (MNV-1) solution and centrifuged at $4300 \times g$ for $30 \mathrm{~min}$ to remove debris. $40 \mathrm{~mL}$ of the supernatant and $10 \mathrm{~mL}$ of sterile PEG solution (100 g PEG-8 000, $6 \mathrm{~g} \mathrm{NaCl}$ in $250 \mathrm{~mL}$ water at $\mathrm{pH} 7.2$ ) were mixed and slowly rotated overnight at $4{ }^{\circ} \mathrm{C}$ (Shieh et al., 1995). The mixture was then centrifuged at $10000 \times g$ for 90 min at $4{ }^{\circ} \mathrm{C}$, and the supernatant was removed. The pellet was dissolved in RLT buffer in a total volume of $300 \mu \mathrm{L}$. For process control, $50 \mathrm{~mL}$ tap water was handled in the same way as the samples.

\section{Extraction of RNA and reverse transcription}

Total RNA extraction was done in a Biorobot EZ1 (Qiagen) with the EZ1 Virus mini kit v.2.0 (Qiagen), according to the manufacturer's protocol. The sample volume was $300 \mu \mathrm{L}$, and the purified RNA was eluted in $60 \mu \mathrm{L}$. Potentially inhibiting components were eliminated by the OneStep ${ }^{\text {TM }}$ PCR Inhibitor Removal Kit (Zymo Research, Irvine, CA). Purified total RNA was stored at $-80^{\circ} \mathrm{C}$ until further processing.

First strand cDNA synthesis was done in a total volume of $40 \mu \mathrm{L}$, containing $20 \mu \mathrm{L}$ purified RNA, $8 \mu \mathrm{L}$ RNase free water, $8 \mu \mathrm{L} 5 \times$ Reaction mix, and $4 \mu \mathrm{L}$ Maxima ${ }^{\mathrm{TM}}$ First Strand cDNA Synthesis RT-qPCR enzyme mix (Thermo Scientific, Stockholm, Sweden) with random N6 primer. Synthesis of CDNA was done at $25^{\circ} \mathrm{C}$ for $10 \mathrm{~min}$, followed by $50^{\circ} \mathrm{C}$ for $15 \mathrm{~min}$. The reaction was stopped at $85^{\circ} \mathrm{C}$ for $5 \mathrm{~min}$, and then the synthesis was cooled to $4^{\circ} \mathrm{C}$. Until further processing, cDNA was stored at $-20^{\circ} \mathrm{C}$. RNase free water was used as a negative control. Reverse transcription step inhibition control was tested with Alien Reference RNA VIC QRT-PCR Detection Kit (Agilent, La Jolla, CA), according to the manufacturer's instructions. 


\section{Detection and quantification by TaqMan real-time PCR}

Quantitative real-time PCR was done as a duplex PCR in an ABI 7500 FAST PCR system (Applied Biosystems). Each sample was tested in duplicate for NoV GGI and GGII. The following thermal cycling was used: $95^{\circ} \mathrm{C}$ for $10 \mathrm{~min}$, followed by 50 cycles of $95^{\circ} \mathrm{C}$ for $15 \mathrm{~s}$ and $56^{\circ} \mathrm{C}$ for $60 \mathrm{~s}$ (data acquisition FAM/JOE). For the quantification of NoV, $2 \mu \mathrm{L}$ of $\mathrm{CDNA}$ was used as a template in a total reaction volume of $25 \mu \mathrm{L}$, containing $200 \mathrm{nM}$ of each primer (NV-G1-fwd1b, NV-G1-rev, NV-G2-fwd and COG2R), and $200 \mathrm{nM}$ of each TaqMan probe (Kageyama et al., 2003; Nordgren et al., 2008). 0.2 $\mu \mathrm{L}$ of ROX $(50 \mu \mathrm{M})$ and $12.5 \mu \mathrm{L}$ Maxima ${ }^{\mathrm{TM}}$ Probe qPCR Master Mix (2X) (Thermo Scientific) were used. A pUC57 plasmid with two inserts (Genscript, Piscataway, NJ), which include the regions of the ORF1ORF2 junction for NoV GGI and GGII, was used as a standard for quantification. The insert for NoV GGI was like Genebank NCBI JX023285.1 position 5286 to 5383, and for NoV GGII it was like AF414417.1 position 485 to 592 . Quantification standards were amplified in duplicate with tenfold dilution series of the plasmid ranging from $10^{6}$ to 10 copies per reaction. The limit of quantification was 15000 genome equivalents $L^{-1}$, and the limit of detection was extrapolated to 4500 genome equivalents $\mathrm{L}^{-1}$.

For the amplification of MNV-1 (used as process control of the virus enrichment and RNA purification) and of the tick borne encephalitis virus (TBEV) (used as process control of the PCR performance), the following primers and probes were used: MNV fwd, MNV rev, F-TBEV 1 SC, R-TBEV 1 SC, MNV-probe, TBEV-probe SC (Persson, 2013; Schwaiger and Cassinotti, 2003). The reaction volume was $25 \mu \mathrm{L}$, containing $300 \mathrm{nM}$ of MNV primer, $100 \mathrm{nM}$ of MNV probe, $200 \mathrm{nM}$ of TBEV primer and probe, $2 \mu \mathrm{L}$ of a 1:100 dilution of TBEV cDNA synthesis, $0.2 \mu \mathrm{L} \operatorname{ROX}(50 \mu \mathrm{M})$, and $12.5 \mu \mathrm{L}$ Maxima $^{\mathrm{TM}}$ Probe $\mathrm{qPCR}$ Master Mix (2X) (Thermo Scientific). The thermal cycling conditions were as follows: $95^{\circ} \mathrm{C}$ for $10 \mathrm{~min}$, followed by 45 cycles of $95^{\circ} \mathrm{C}$ for $15 \mathrm{~s}$ and $60^{\circ} \mathrm{C}$ for $60 \mathrm{~s}$ (data acquisition FAM/JOE). The individual filtration performance on a per sample basis was estimated from the quantification cycle value (Cp) value of MNV-1 in the sample.

\section{Appendix B: Quantifying E. coli reduction at the drinking water treatment plant}

\section{Statistical models}

Statistical models presented by Teunis et al. (1999) for describing microbial fractions from count data have been modified and applied to describe the counts of $E$. coli before and after the treatment barriers at the Överby drinking water treatment plant (DWTP).

\section{E. coli concentration before treatment}

The entire sample of $E$. coli measurements $(n=212)$ in the source water was used to describe the source water concentration. Concentration before treatment was assumed to follow a gamma distribution, therefore, counts ( $n$ colonies in volume $v$ ) of $E$. coli before treatment were assumed to follow a negative binomial distribution:

Equation B.1

$$
f(n \mid \lambda, \rho, v)=\frac{\lambda^{-\rho} v^{n}\left(\frac{1}{\lambda}+v\right)^{-n-\rho} \Gamma[n+\rho]}{n ! \Gamma[\rho]}
$$

where $\Gamma[x]$ is the Euler gamma function. 
For a given dataset of $m$ counts $\left(n_{i}\right)$ in a constant sample volume $v$, the likelihood function (the function describing the distribution of parameter values given the data) is given by:

Equation B.2

$$
L\left(\lambda, \rho, \mid n_{i}, v\right)=\prod_{i=1}^{m} f\left(\lambda, \rho \mid n_{i}, v\right)
$$

The values of $\lambda$ and $\rho$ that maximise the likelihood function are termed the maximum likelihood estimators (MLE) of the parameters.

A minor modification to the models presented by Teunis et al. (1999) was applied to account for left and right censored data. For left censored data $(<1)$, the count was assumed to be zero and hence the contribution to the likelihood was given by:

Equation B.3

$$
f(\lambda, \rho \mid 0,0.1)
$$

For right censored data $(>x)$, the contribution to the likelihood was given by:

Equation B.4

$$
\left(1-\sum_{i=0}^{x} f(\lambda, \rho \mid i, 0.1)\right)
$$

\section{E. coli concentration after treatment}

The concentration of $E$. coli after treatment was assumed to be given by $\pi c$ where $c$ is the concentration before treatment, and $\pi$ is the probability that an organism is able to pass the treatment barrier. The counts ( $k$ colonies in volume $v$ ) of $E$. coli following treatment were therefore assumed to follow a negative binomial distribution:

Equation B.5

$$
h(k \mid \lambda, \rho, v, \pi)=\frac{\lambda^{-\rho}(\pi v)^{k}\left(\frac{1}{\lambda}+\pi v\right)^{-k-\rho} \Gamma[k+\rho]}{k ! \Gamma[\rho]}
$$

\section{Constant removal}

If the performance of the treatment barrier is assumed to be constant, then the likelihood function for the input ( $m$ counts before) and output ( $/$ counts after) samples is given by:

Equation B.6

$$
L\left(\lambda, \rho, \pi \mid n_{i}, k_{j}\right)=\prod_{i=1}^{m}\left\{f\left(\lambda, \rho \mid n_{i}, 0.1\right)\right\}^{\delta_{i}} \cdot\left\{\left(1-\sum_{\gamma=1}^{n_{i}} f(\lambda, \rho \mid \gamma, 0.1)\right)\right\}^{1-\delta_{i}} \cdot \prod_{j=1}^{l}\left[h\left(\lambda, \rho, \pi \mid k_{j}, 0.1\right)\right]
$$

where $\delta=1$ for exact counts, and 0 for right censored counts. For left censored data, the count is zero and hence the likelihood is given by $f(\lambda, \rho \mid 0,0.1)$.

\section{Variable removal}

If the removal is assumed to vary according to a Beta distribution $\pi^{\sim} \operatorname{Beta}(\alpha, \beta)$, then the counts $(k)$ of E. coli after treatment are assumed to follow the distribution:

\section{Equation B.7}

$$
g(k \mid \lambda, \rho, \alpha, \beta, v)=\int_{\pi=0}^{1} \frac{\lambda^{-\rho}(\pi v)^{k}\left(\frac{1}{\lambda}+\pi v\right)^{-k-\rho} \Gamma[k+\rho]}{k ! \Gamma[\rho]} \cdot \frac{\Gamma(\alpha+\beta)}{\Gamma(\alpha) \Gamma(\beta)} \pi^{\alpha-1}(1-\pi)^{\beta-1} \mathrm{~d} \pi
$$




\section{Equation B.8}

$$
g(k \mid \lambda, \rho, \alpha, \beta, v)=\frac{\lambda^{k} v^{k} \Gamma[\beta] \Gamma[\alpha+k] \Gamma[k+\rho] \operatorname{H} 2 \mathrm{~F} 1[\alpha+k, k+\rho, \alpha+\beta+k,-\lambda v]}{\operatorname{Beta}[\alpha, \beta] k ! \operatorname{Gamma}[\rho]}
$$

where $\mathrm{H} 2 \mathrm{~F} 1$ is a Hypergeometric Function.

The likelihood function for the input ( $m$ counts) and output (/ counts) samples is given by: Equation B.9

$$
L(\lambda, \rho, \alpha, \beta \mid n, k)=\prod_{i=1}^{m}\left\{f\left(\lambda, \mu \mid n_{i}, 0.1\right)\right\}^{\delta_{i}} \cdot\left\{\left(1-\sum_{j=1}^{n_{i}} f(\lambda, \rho \mid j, 0.1)\right)\right\}^{1-\delta_{i}} \cdot \prod_{i=1}^{l}[g(\lambda, \rho, \alpha, \beta \mid k, 0.1)]
$$

where $\delta=1$ for exact counts, and 0 for right censored counts. For left censored data, the count is assumed to be zero and hence the likelihood is given by $f(\lambda, \rho \mid 0,0.1)$.

The likelihood functions were constructed in Mathematica 8.0 and optimised to obtain MLE of all parameters.

\section{Model fitting and results}

Historical monitoring E. coli data were available for the source water; following each rapid sand filter; and following each slow sand filter. The above statistical models were fitted to the $E$. coli data to characterise rapid sand filtration and slow sand filtration. The datasets used to characterise the $E$. coli concentration before and after these treatment barriers are summarised in Table B.1.

\section{Rapid sand filtration}

MLE for parameters of the constant and the variable removal models fitted to datasets before and after rapid sand filtration are summarised in Table B.2. The estimated removal varied between 1.78 and $3.15 \log _{10}$. The variable model could not be fitted across Filter 4 . The reduction in the deviance by applying the variable model only produced a significant improvement in fit for Filter 2 (14.58 $>\chi^{2} 0.95,1=3.84$ ), Filters 1 and 3 were adequately fit by the constant removal model. When all outflows were combined, the variable removal model produced a significant improvement in fit $(22.72$ $\left.>\chi^{2} 0.95,1=3.84\right)$. The maximum likelihood beta distribution describing removal across all filters is illustrated (with 95\% credible interval) in Figure B.1.

\section{Slow sand filtration}

MLE for the model parameters for the constant removal model are summarised in Table B.2. In addition, due to the small number of detects in the finished water, it was not meaningful to fit the variable removal model to the dataset. The $\log _{10}$ reduction varied between filters from 0.64 to 1.11 . Only a low level of removal could be demonstrated by the data since the inflow concentration was low. 
Table B.1 E. coli data before and after treatment barriers at the Överby DWTP for quantifying reduction

\begin{tabular}{lll}
\hline Process characterised & Data before & Data after \\
\hline Rapid sand filtration & $\begin{array}{l}\text { Counts in source water } \\
(n=212)\end{array}$ & $\begin{array}{l}\text { Counts after each filter }(4 \times n=44) \\
\text { Combined outflow }(n=176)\end{array}$ \\
\hline Slow sand filtration & $\begin{array}{l}\text { Combined counts in rapid } \\
\text { sand filtration effluent } \\
(n=176)\end{array}$ & $\begin{array}{l}\text { Counts after each filter }(4 \times n=44) \\
\text { Combined outflow }(n=176)\end{array}$ \\
\hline
\end{tabular}

Table B.2 Maximum likelihood estimators of all parameters and deviance for constant and variable removal models fitted to the datasets from the outflow of each individual filter, and the combined outflow

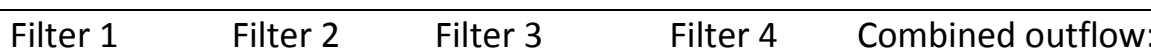

all filters

\begin{tabular}{|c|c|c|c|c|c|}
\hline \multicolumn{6}{|c|}{ Rapid sand filtration } \\
\hline \multicolumn{6}{|c|}{ Constant Removal } \\
\hline$\lambda$ & 872 & 963 & 888 & 860 & 1055 \\
\hline$\rho$ & 0.37 & 0.34 & 0.36 & 0.37 & 0.32 \\
\hline $\log _{10}(\pi)$ & -2.15 & -1.78 & -1.90 & -3.15 & -2.06 \\
\hline Deviance & 1392.59 & 1413.10 & 1412.28 & 1352.92 & 1559.15 \\
\hline \multicolumn{6}{|c|}{ Variable removal } \\
\hline$\lambda$ & 861 & 859 & 861 & - & 860 \\
\hline$\rho$ & 0.37 & 0.37 & 0.37 & - & 0.37 \\
\hline$\alpha$ & 0.89 & 0.086 & 0.62 & - & 0.19 \\
\hline$\beta$ & 122.20 & 4.28 & 44.95 & - & 19.29 \\
\hline Deviance & 1392.07 & 1398.52 & 1411.11 & - & 1536.43 \\
\hline \multicolumn{6}{|c|}{ Slow sand filtration } \\
\hline \multicolumn{6}{|c|}{ Constant Removal } \\
\hline$\lambda$ & 40.15 & 45.03 & 40.15 & 42.75 & 46.67 \\
\hline$\rho$ & 0.074 & 0.066 & 0.074 & 0.069 & 0.063 \\
\hline $\log _{10}(\pi)$ & -1.10 & -0.64 & -1.11 & -0.81 & -0.88 \\
\hline Deviance & 202.96 & 208.83 & 202.96 & 206.51 & 243.03 \\
\hline
\end{tabular}




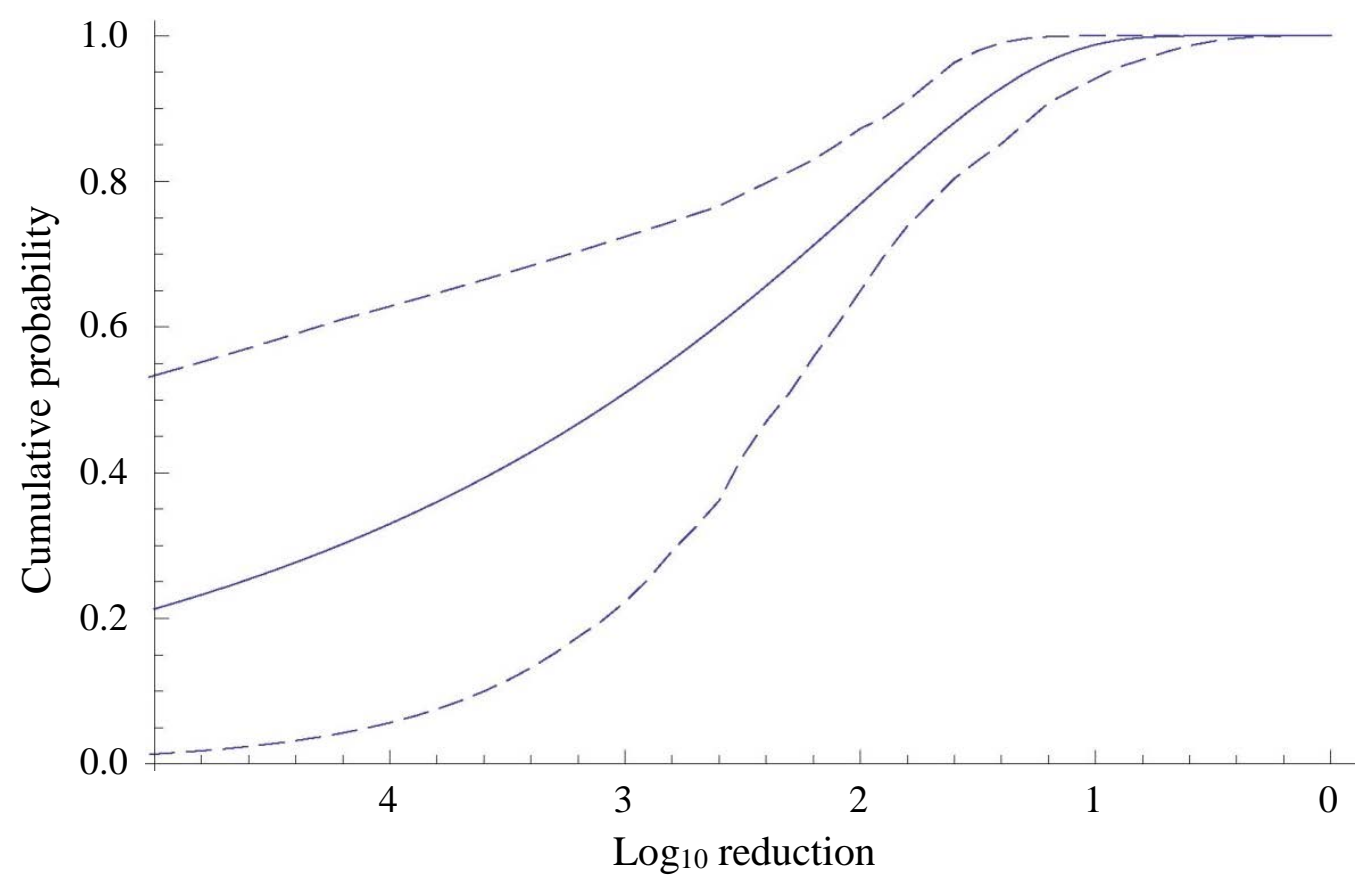

Figure B.1 Beta distribution cumulative density function for removal of $E$. coli by rapid sand filtration at the Överby DWTP (combined result for all four filters). Maximum likelihood (solid line) and $95 \%$ credible interval (dashed lines).

\section{References}

Åström J, Petterson S, Bergstedt O, Pettersson TJR, Stenström TA. Evaluation of the microbial risk reduction due to selective closure of the raw water intake before drinking water treatment. J. Water Health 2007; 5: 81-97.

Bae J, Schwab KJ. Evaluation of murine norovirus, feline calicivirus, poliovirus, and MS2 as surrogates for human norovirus in a model of viral persistence in surface water and groundwater. Appl. Environ. Microbiol. 2008; 74: 477-484.

Bellou MI, Syngouna VI, Tselepi MA, Kokkinos PA, Paparrodopoulos SC, Vantarakis A, et al. Interaction of human adenoviruses and coliphages with kaolinite and bentonite. Sci. Total Environ. 2015; 517: 86-95.

Braeye T, De Schrijver K, Wollants E, van Ranst M, Verhaegen J. A large community outbreak of gastroenteritis associated with consumption of drinking water contaminated by river water, Belgium, 2010. Epidemiol. Infect. 2014.

Craun GF, Brunkard JM, Yoder JS, Roberts VA, Carpenter J, Wade T, et al. Causes of outbreaks associated with drinking water in the United States from 1971 to 2006. Clin. Microbiol. Rev. 2010; 23: 507-528.

Cromeans TL, Kahler AM, Hill VR. Inactivation of adenoviruses, enteroviruses, and murine norovirus in water by free chlorine and monochloramine. Appl. Environ. Microbiol. 2010; 76: 10281033.

DHI. MIKE 21 \& MIKE 3 Flow Model FM Hydrodynamic and Transport Module - Scientific Documentation. DHI Water \& Environment, Horsholm, 2011.

Dienus O, Nyström F, Sokolova E, Matussek A, Pettersson TJR, Löfgren S, et al. Norovirus long-term dynamics in wastewater discharges and in the recipient drinking water sources along the river Göta älv, Sweden. Manuscript 2015.

Hewitt J, Leonard M, Greening GE, Lewis GD. Influence of wastewater treatment process and the population size on human virus profiles in wastewater. Water Res. 2011; 45: 6267-6276. 
Hijnen WAM, Medema GJ. Elimination of micro-organisms by drinking water treatment processes: A review: KWR Watercycle Research Institute, IWA Publishing, 2010.

Hipsey MR, Antenucci JP, Brookes JD. A generic, process-based model of microbial pollution in aquatic systems. Water Resour. Res. 2008; 44.

Kageyama T, Kojima S, Shinohara M, Uchida K, Fukushi S, Hoshino FB, et al. Broadly reactive and highly sensitive assay for Norwalk-like viruses based on real-time quantitative reverse transcription-PCR. J. Clin. Microbiol. 2003; 41: 1548-1557.

Kahler AM, Cromeans TL, Roberts JM, Hill VR. Effects of source water quality on chlorine inactivation of adenovirus, coxsackievirus, echovirus, and murine norovirus. Appl. Environ. Microbiol. 2010; 76: 5159-5164.

Kemmeren JM, Mangen MJJ, Duynhoven YTHPv, Havelaar AH. Priority setting of foodborne pathogens: disease burden and costs of selected enteric pathogens. Prioritering van voedsel overdraagbare pathogenen: ziektelast en ziektegebonden kosten. Rijksinstituut voor Volksgezondheid en Milieu RIVM, 2006.

Larsson C, Andersson Y, Allestam G, Lindqvist A, Nenonen N, Bergstedt O. Epidemiology and estimated costs of a large waterborne outbreak of norovirus infection in Sweden. Epidemiol. Infect. 2014; 142: 592-600.

Lim MY, Kim JM, Ko G. Disinfection kinetics of murine norovirus using chlorine and chlorine dioxide. Water Res. 2010; 44: 3243-3251.

Liu L, Phanikumar MS, Molloy SL, Whitman RL, Shively DA, Nevers MB, et al. Modeling the transport and inactivation of $\mathrm{E}$. coli and enterococci in the near-shore region of Lake Michigan. Environ. Sci. Technol. 2006; 40: 5022-5028.

Mac Kenzie WR, Hoxie NJ, Proctor ME, Gradus MS, Blair KA, Peterson DE, et al. A Massive Outbreak in Milwaukee of Cryptosporidium Infection Transmitted through the Public Water Supply. New Engl. J. Med. 1994; 331: 161-167.

Mathijs E, Stals A, Baert L, Botteldoorn N, Denayer S, Mauroy A, et al. A Review of Known and Hypothetical Transmission Routes for Noroviruses. Food Environ. Virol. 2012; 4: 131-152.

Matthews JE, Dickey BW, Miller RD, Felzer JR, Dawson BP, Lee AS, et al. The epidemiology of published norovirus outbreaks: A review of risk factors associated with attack rate and genogroup. Epidemiol. Infect. 2012; 140: 1161-1172.

McBride GB, Stott R, Miller W, Bambic D, Wuertz S. Discharge-based QMRA for estimation of public health risks from exposure to stormwater-borne pathogens in recreational waters in the United States. Water Res. 2013; 47: 5282-5297.

McBride GB, Stott R, Papps D, Palliser C, Jenner G, Macdonald G. Estimating health risks to water users: Marrying hydrodynamic models and risk models. Water Practice and Technology 2012; 7.

Medema G, Smeets P. Quantitative risk assessment in the Water Safety Plan: Case studies from drinking water practice. Water Science and Technology: Water Supply 2009; 9: 127-132.

Ngazoa ES, Fliss I, Jean J. Quantitative study of persistence of human norovirus genome in water using TaqMan real-time RT-PCR. J. Appl. Microbiol. 2008; 104: 707-715.

Nordgren J, Bucardo F, Dienus O, Svensson L, Lindgren PE. Novel light-upon-extension real-time PCR assays for detection and quantification of genogroup I and II noroviruses in clinical specimens. J. Clin. Microbiol. 2008; 46: 164-170.

Nordgren J, Matussek A, Mattsson A, Svensson L, Lindgren PE. Prevalence of norovirus and factors influencing virus concentrations during one year in a full-scale wastewater treatment plant. Water Res. 2009; 43: 1117-1125.

Pérez-Sautu U, Sano D, Guix S, Kasimir G, Pintó RM, Bosch A. Human norovirus occurrence and diversity in the Llobregat river catchment, Spain. Environ. Microbiol. 2012; 14: 494-502.

Persson S. Molecular characterization of a murine norovirus isolate from Sweden and detection of noroviruses in artificially contaminated raspberries. Faculty of Veterinary Medicine and Animal Science. Uppsala University, Department of Biomedical Sciences and Veterinary Public Health, 2013, pp. 32. 
Petterson S, Stenström TA. Quantification of pathogen inactivation efficacy by free chlorine disinfection of drinking water for QMRA. J. Water Health 2015; In Press, uncorrected proof available online 19 February, 2015; doi:10.2166/wh.2015.193.

Petterson SR, Stenström TA. Generic QMRA tool for drinking water systems modelling. WaterMicro 2007, 14th International symposium on health-related water microbiology, Tokyo 2007.

Rohayem J. Norovirus seasonality and the potential impact of climate change. Clin. Microbiol. Infec. 2009; 15: 524-527.

Rutjes SA, Lodder WJ, Van Leeuwen AD, De Roda Husman AM. Detection of infectious rotavirus in naturally contaminated source waters for drinking water production. J. Appl. Microbiol. 2009; 107: 97-105.

Schijven JF, Teunis PFM, Rutjes SA, Bouwknegt M, De Roda Husman AM. QMRAspot: A tool for Quantitative Microbial Risk Assessment from surface water to potable water. Water Res. 2011; 45: 5564-5576.

Schwaiger M, Cassinotti P. Development of a quantitative real-time RT-PCR assay with internal control for the laboratory detection of tick borne encephalitis virus (TBEV) RNA. J. Clin. Virol. 2003; $27:$ 136-45.

Seitz SR, Leon JS, Schwab KJ, Lyon GM, Dowd M, McDaniels M, et al. Norovirus infectivity in humans and persistence in water. Appl. Environ. Microbiol. 2011; 77: 6884-6888.

Shieh YSC, Wait D, Tai L, Sobsey MD. Methods to remove inhibitors in sewage and other fecal wastes for enterovirus detection by the polymerase chain reaction. J. Virol. Methods 1995; 54: 5166.

Smeets PWMH, Rietveld LC, Van Dijk JC, Medema GJ. Practical applications of quantitative microbial risk assessment (QMRA) for water safety plans. Water Sci. Technol. 2010; 61: 1561-1568.

Sokolova E, Pettersson TJR, Bergstedt O, Hermansson M. Hydrodynamic modelling of the microbial water quality in a drinking water source as input for risk reduction management. J. Hydrol. 2013; 497: 15-23.

Teunis PFM, Evers EG, Slob W. Analysis of Variable Fractions Resulting from Microbial Counts. Quantitative Microbiology 1999; 1: 63-88.

Teunis PFM, Moe CL, Liu P, Miller SE, Lindesmith L, Baric RS, et al. Norwalk virus: How infectious is it? J. Med. Virol. 2008; 80: 1468-1476.

Teunis PFM, Rutjes SA, Westrell T, de Roda Husman AM. Characterization of drinking water treatment for virus risk assessment. Water Res. 2009; 43: 395-404.

Thebault A, Teunis PFM, Le Pendu J, Le Guyader FS, Denis JB. Infectivity of GI and GII noroviruses established from oyster related outbreaks. Epidemics 2013; 5: 98-110.

Thurston-Enriquez JA, Haas CN, Jacangelo J, Gerba CP. Chlorine inactivation of adenovirus type 40 and feline calicivirus. Appl. Environ. Microbiol. 2003; 69: 3979-3985.

Verhoef L, Depoortere E, Boxman I, Duizer E, Van Duynhoven Y, Harris J, et al. Emergence of new norovirus variants on spring cruise ships and prediction of winter epidemics. Emerg. Infect. Dis. 2008; 14: 238-243.

Westrell T, Anderson Y, Stenström TA. Drinking water consumption patterns in Sweden. J. Water Health 2006a; 4: 511-522.

Westrell T, Teunis P, van den Berg H, Lodder W, Ketelaars H, Stenström TA, et al. Short- and longterm variations of norovirus concentrations in the Meuse river during a 2-year study period. Water Res. 2006b; 40: 2613-2620.

WHO. Guidelines for drinking-water quality, fourth edition. Geneva: World Health Organization, 2011.

Wong K, Mukherjee B, Kahler AM, Zepp R, Molina M. Influence of inorganic ions on aggregation and adsorption behaviors of human adenovirus. Environ. Sci. Technol. 2012; 46: 11145-11153.

Xagoraraki I, Yin Z, Svambayev Z. Fate of viruses in water systems. J. Environ. Eng. ASCE 2014; 140. 